\title{
Practical approaches to sedation and analgesia in the newborn
}

\author{
Christopher McPherson $\mathbb{1}^{1,2} \cdot$ Cynthia M. Ortinau ${ }^{1} \cdot$ Zachary Vesoulis $^{1}$
}

Received: 21 August 2020 / Revised: 6 October 2020 / Accepted: 12 November 2020 / Published online: 29 November 2020

(c) The Author(s), under exclusive licence to Springer Nature America, Inc. 2020

\begin{abstract}
The prevention, assessment, and treatment of neonatal pain and agitation continues to challenge clinicians and researchers. Substantial progress has been made in the past three decades, but numerous outstanding questions remain. In this setting, clinicians must establish safe and compassionate standardized practices that consider available efficacy data, long-term outcomes, and research gaps. Novel approaches with limited data must be carefully considered against historic standards of care with robust data suggesting limited benefit and clear adverse effects. This review summarizes available evidence while suggesting practical clinical approaches to pain assessment and avoidance, procedural analgesia, postoperative analgesia, sedation during mechanical ventilation and therapeutic hypothermia, and the issues of tolerance and withdrawal. Further research in all areas represents an urgent priority for optimal neonatal care. In the meantime, synthesis of available data offers clinicians challenging choices as they balance benefit and risk in vulnerable critically ill neonates.
\end{abstract}

\section{Introduction}

As recently as 30 years ago, preterm neonates underwent major surgical procedures without perioperative or postoperative analgesia [1]. Careful investigation, including basic science and clinical research, documented the unique susceptibility of preterm neonates to adverse metabolic, behavioral, and clinical responses to acute pain, sparking a revolution in pain science in neonatal intensive care $[2,3]$. Increasing evidence suggests that pain is a central factor predicting brain dysmaturation, especially in babies born very preterm and in those with many early exposures to pain [4]. Pain in neonatal life also has profound long-term developmental impacts [5]. In this context, the accurate assessment and diligent avoidance of pain are vital, although a consensus, standardized approach has yet to be achieved. Nonpharmacologic comfort measures and sucrose should be utilized for procedural pain; however, the optimal bundle of interventions remains undefined. Provision of analgesia prior to major invasive procedures ranging from

Christopher McPherson

mcphersonc@wustl.edu

1 Department of Pediatrics, Washington University School of Medicine, St. Louis, MO, USA

2 Department of Pharmacy, St. Louis Children's Hospital, St. Louis, MO, USA endotracheal intubation to surgery represents standard neonatal care. Investigation of the short-term and long-term safety of newer analgesic and anesthetic agents presents on ongoing challenge. The optimal approach to preterm and term neonates experiencing agitation during invasive mechanical ventilation remains unclear. In addition, clinicians must address drug tolerance and iatrogenic withdrawal in patients requiring long-term pharmacologic sedation and/or analgesia. Finally, the ideal approach to prevent agitation and shivering during therapeutic hypothermia requires careful consideration. This review summarizes available evidence addressing these areas of clinical controversy, offering practical approaches for clinicians and highlighting areas of urgent research need for investigators.

\section{Assessment of neonatal pain and agitation}

\section{Defining pain}

NICU hospitalization may require a broad range of painful interventions, including skin breaks for laboratory testing, intravenous line placement, and invasive mechanical ventilation. Historically, considerable debate has surrounded conscious pain perception in the newborn, due to the nonverbal nature of neonates [6]. Landmark work in the late 20th century brought awareness that nociception and associated physiological adverse effects occur even at the lowest limits of human viability [2]. Unfortunately, methods of 
real-time, direct measure of nociception do not exist for neonates. In the absence of tools that clearly assess the necessity and effect of nonpharmacologic and pharmacologic treatment, clinicians must rely on subjective behavioral responses and surrogate physiological markers.

\section{Pain scales}

Neonatal pain assessment tools are predominantly designed to assess procedural and postoperative pain or acute distress with handling. These scales generally include physiologic, behavioral, and contextual components. Five established neonatal assessment tools are summarized in Table 1. All of these tools can discern painful from stressful stimuli and have very high intraclass correlations for pain assessment during venipuncture [7]. Further, the N-PASS can also be used to assess chronic pain/agitation during mechanical ventilation [8]. Each neonatal unit should choose one tool that best suits the breadth of that unit's practices. Caregivers should be rigorously trained on the selected tool to ensure consistent assessment before, during, and after painful procedures and during routine assessments, such as care during invasive mechanical ventilation.

\section{Objective measures of pain}

For decades, investigators have tried to identify reliable, noninvasive, and reproducible technologies for objectively assessing neonatal pain and stress. Electroencephalography, near-infrared spectroscopy (NIRS), skin conductance, and salivary cortisol all discriminate noxious painful stimuli from light touch $[9,10]$. NIRS, heart rate, and oxygen saturation can capture an acute pain response, whereas a chronic stressful response is better captured by skin conductance and salivary cortisol in term neonates [11]. These objective methods show mild-to-moderate correlation with behavioral assessment. However, it is still unclear which of these techniques, individually or in combination with pain scales, has the strongest reliability for assessing acute and chronic pain and stress in infancy. Thus, bedside application remains challenging.

\section{Avoidance of pain and agitation}

While some painful procedures are essential in the care of the critically ill newborn, limitation or avoidance of others may be feasible. Phlebotomy, frequently performed by painful heel lance, is one such procedure. A thoughtful and judicious approach to the number and frequency of peripheral blood samples should be employed to reduce painful events [12]. Replacement of laboratory-based assays with noninvasive measurements, such as substitution of frequent

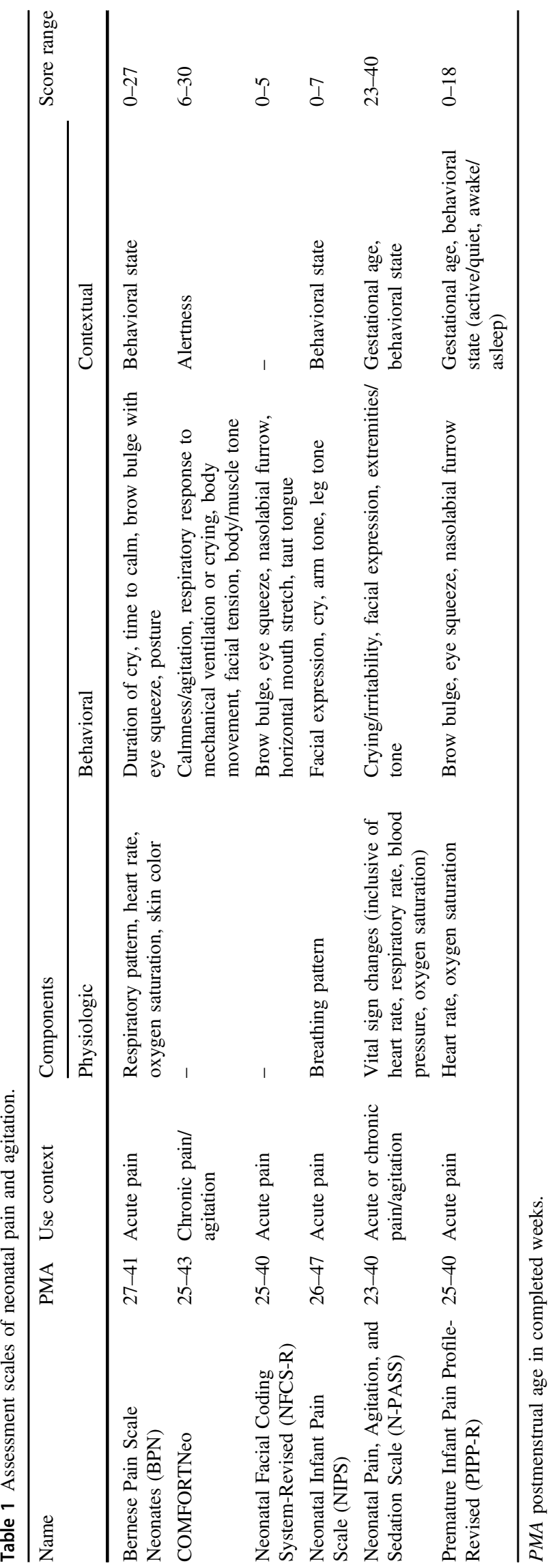


blood gas analysis with a transcutaneous carbon dioxide monitor, may be appropriate. Recent efforts in respiratory management of very preterm neonates include immediate use of continuous positive airway pressure in the delivery room, early extubation, and strategies for decreasing rates of unplanned extubation. While the impact of such efforts have not been studied in relation to pain, a standardized approach that limits intubation attempts and length of invasive mechanical ventilation should be utilized.

\section{Procedural analgesia}

Routine neonatal care involves many procedures that range from minimally invasive skin breaks to major surgery. Although analgesia prior to major procedures is now standard neonatal care, the relative short-term and long-term safety of newer analgesic and anesthetic agents challenges investigators and clinicians [13]. Thus, procedural analgesia should balance the risk of untreated pain with the side effects of intervention, known and unknown [14]. Treatment should be titrated based on the anticipated amplitude and duration of pain. For example, treatment for minimally invasive procedures centers on nonpharmacologic interventions and sucrose, whereas endotracheal intubation and postoperative care incorporate a variety of pharmacologic agents.

\section{Minimally invasive procedures}

\section{Nonpharmacologic intervention}

Optimal treatment of pain and agitation in neonates requires a multimodal approach that always includes nonpharmacologic strategies. Nonnutritive sucking, breast milk, skin-to-skin contact, kangaroo care, and facilitated tucking are all aspects of developmental care that are efficacious for reducing the physiologic and behavioral pain response to minimally invasive procedures such as needle sticks [15]. Facilitated tucking improves both pain reactivity and immediate regulation in preterm neonates, while nonnutritive sucking impacts both domains in term neonates, emphasizing the importance of tailoring nonpharmacologic therapy bundles based on neonatal maturity [16]. Although the optimal bundle of nonpharmacologic interventions remains undefined, individual neonatal units should select the most feasible, evidence-based interventions and consistently utilize them prior to all mild to moderately painful procedures.

\section{Sucrose}

Clinical trials of oral administration of sucrose prior to heel lance, venipuncture, and intramuscular injection consistently show reduced crying, facial grimacing, and motor activity in neonates [17]. Although sucrose demonstrates benefit for behavioral responses, there is no impact on oxygen consumption or energy expenditure, salivary or plasma cortisol concentrations, or neural activity of nociception-evoked circuits in the spinal cord or brain [17]. Sucrose also does not prevent development of remote hyperalgesia in neonates, and there is no benefit for brain growth, brain connectivity, or rates of neurodevelopmental impairment at 18 months of age [18].

The mechanism by which sucrose improves behavioral responses to pain may include stimulation of endogenous opioid, dopaminergic, cholinergic, and/or serotonergic pathways. Of relevance, chronic in utero stimulation of these pathways may have detrimental implications for development of motor function and attention [19]. Data in preterm neonates show impaired motor function and difficulties with attention/orientation at term-equivalent age when $>10$ doses per day of $0.1 \mathrm{~mL}$ of $24 \%$ oral sucrose are administered in the first week of life [20]. Thus, the lack of objective efficacy and potential for adverse consequences at high cumulative doses should prompt clinicians to utilize sucrose judiciously. Specifically, use should be limited to the minimum effective dose $(0.1 \mathrm{~mL}$ of $24 \%$ solution $)$ with administration restricted to invasive procedures that illicit mild-moderate pain [21].

\section{Endotracheal intubation}

Endotracheal intubation is often necessary for cardiorespiratory stabilization in neonates but may cause acute distress. Disruption of physiologic homeostasis by intubation may result in hypoxemia, bradycardia via vagal stimulation, and systemic, pulmonary, and intracranial hypertension [22]. Premedication with a variety of analgesics, sedatives, vagolytics, and muscle relaxants minimizes airway trauma and physiologic instability (Table 2) [23]. Premedication also reduces procedure time and number of attempts, regardless of the experience of the operator [24].

\section{Analgesia}

The ideal analgesic agent for endotracheal intubation should have a rapid onset, short duration of action, and minimal impact on respiratory mechanics. Opioids, such as remifentanil and fentanyl, are options that provide analgesia via agonism of G-protein-coupled $\mu$-opioid receptors. Remifentanil produces favorable intubation conditions that improve first-attempt success when compared to an opioid with slower onset (morphine) [25]. Remifentanil distributes within $1 \mathrm{~min}$ of intravenous administration and has an elimination half-life of $5.4 \mathrm{~min}$ in neonates. Fentanyl also distributes almost immediately on intravenous 
Table 2 Pharmacokinetic and clinical data for selection of optimal premedication for endotracheal intubation.

\begin{tabular}{|c|c|c|c|c|}
\hline \multirow[t]{2}{*}{ Agent } & \multirow[t]{2}{*}{ Class } & \multicolumn{2}{|c|}{ Pharmacokinetic data } & \multirow[t]{2}{*}{ Clinical notes } \\
\hline & & Onset & Duration & \\
\hline Atropine & Vagolytic & $1 \min ^{\mathrm{a}}$ & $2 \mathrm{~h}$ & - Eliminates vagally mediated bradycardia events during intubation \\
\hline Cisatracurium & Muscle relaxant & $2-3 \min$ & $35-45 \mathrm{~min}$ & - Minimal neonatal data \\
\hline Fentanyl & Opioid analgesic & $1 \min ^{\mathrm{b}}$ & Half-life $9.5 \mathrm{~h}$ & $\begin{array}{l}\text { - Produces superior intubating conditions to remifentanil when given with } \\
\text { muscle relaxant } \\
\text { - Produces stiff chest with rapid administration } \\
\text { - May prolong time required to successful extubation }\end{array}$ \\
\hline Glycopyrrolate & Vagolytic & $1 \mathrm{~min}$ & $2 \mathrm{~h}$ & - Minimal neonatal data \\
\hline Midazolam & Sedative hypnotic & $1-2 \min ^{c}$ & Half-life $6.3 \mathrm{~h}$ & $\begin{array}{l}\text { - Improves pain scores and reduces physiologic changes when combined } \\
\text { with fentanyl } \\
\text { - Produces clinically significant hypotension in high proportion of preterm } \\
\text { neonates }\end{array}$ \\
\hline Morphine & Opioid analgesic & $5-15 \min$ & Half-life $10 \mathrm{~h}$ & $\begin{array}{l}\text { - No impact on physiologic adverse effects when given } \leq 5 \text { min prior to } \\
\text { intubation }\end{array}$ \\
\hline Pancuronium & Muscle relaxant & $2-5 \min$ & $2-3 \mathrm{~h}$ & - With atropine, reduces physiologic disturbances \\
\hline Propofol & Sedative hypnotic & $1 \mathrm{~min}$ & Half-life $13 \mathrm{~min}$ & $\begin{array}{l}\text { - Improves oxygen saturations and minimizes procedure time compared } \\
\text { to opioid } \\
\text { - Produces clinically significant hypotension in high proportion of preterm } \\
\text { neonates }\end{array}$ \\
\hline Remifentanil & Opioid analgesic & $1 \min ^{\mathrm{d}}$ & Half-life $5.4 \mathrm{~min}$ & $\begin{array}{l}\text { - Produces good or excellent intubating conditions; extubation possible } \\
\text { within } 20 \mathrm{~min} \\
\text { - Produces stiff chest with rapid administrations }\end{array}$ \\
\hline Rocuronium & Muscle relaxant & $1-3 \min ^{\mathrm{e}}$ & $40-60 \mathrm{~min}$ & - With opioid and atropine, improves success rate on first attempt \\
\hline Succinylcholine & Muscle relaxant & $1 \min ^{\mathrm{f}}$ & $6-8 \min$ & $\begin{array}{l}\text { - With atropine, reduces physiologic disturbances and facilitates more rapid } \\
\text { successful intubation }\end{array}$ \\
\hline Vecuronium & Muscle relaxant & $2-3 \mathrm{~min}$ & $50-70 \mathrm{~min}$ & - With opioid, produces good intubating conditions \\
\hline
\end{tabular}

Pharmacokinetic data presented as mean values in studies of preterm neonates when available; values are extrapolated from more mature populations when neonatal data are unavailable.

antramuscular dosing increases onset to 15-30 min.

${ }^{\mathrm{b}}$ Intranasal dosing increases onset to $5-10 \mathrm{~min}$

${ }^{\mathrm{c}}$ Intranasal dosing increases onset to $5 \mathrm{~min}$.

${ }^{\mathrm{d}}$ Intranasal dosing increases onset to $3 \mathrm{~min}$.

e Intramusclar dosing increases onset to $7 \mathrm{~min}$ and duration to $2 \mathrm{~h}$.

f Intramusclar dosing increases onset to $4 \mathrm{~min}$ and duration to $16 \mathrm{~min}$.

administration, but has a longer elimination half-life of 5.2 and $9.5 \mathrm{~h}$ in term and preterm neonates, respectively. Thus, in clinical scenarios where the intubation, surfactant therapy, extubation (INSURE) approach is used, the long halflife of fentanyl may confound attempts at immediate extubation [26].

It is important for the clinician to be aware of data on methods of administration of these opioids. Neonatal units must have easy access to dilute remifentanil $(20 \mathrm{mcg} / \mathrm{mL}$, stable for $24 \mathrm{~h}$ ) or fentanyl $(5 \mathrm{mcg} / \mathrm{mL}$, stable for 90 days) prepared sterilely in a pharmacy [27]. Bedside manipulation of the commercially available $50-\mathrm{mcg} / \mathrm{mL}$ intravenous solutions should be avoided. Intravenous administration must occur via a syringe pump over a minimum of $3 \mathrm{~min}$ to avoid chest wall rigidity [28]. In some circumstances, neonates without intravenous access require intubation. In this circumstance, intravenous remifentanil or fentanyl can be administered intranasally $[29,30]$.

\section{Sedation}

Sedation for endotracheal intubation can be provided with midazolam, a benzodiazepine. Midazolam binds gammaaminobutyric acid $(\mathrm{GABA})_{\mathrm{A}}$ receptors and promotes hyperpolarization of the neuron through chloride influx. Hypnotic activity occurs within 1-2 min, with a median plasma elimination half-life of $6.3 \mathrm{~h}$ in preterm neonates. When utilized in conjunction with analgesia, midazolam further improves intubating conditions, lowers pain scale scores, and reduces disruption of physiologic homeostasis [31]. Intranasal midazolam can also be used for sedation in appropriately selected patients without intravenous access [32]. It is 
important to note that midazolam should not be used alone for endotracheal intubation. Midazolam should also not be included in premedication of preterm neonates $<34$ weeks corrected gestational age, because of an unacceptable risk of desaturation and/or hypotension in this population [33, 34].

\section{Alternative agents}

Recent investigations have focused on propofol and ketamine as potential single-agents for analgesia and sedation prior to intubation. Propofol provides analgesia, sedation, and amnesia via agonism of $\mathrm{GABA}_{\mathrm{A}}$ receptors and antagonism of N-methyl-D-aspartate (NMDA) receptors. Propofol distributes almost immediately and has a median elimination half-life of $13 \mathrm{~min}$ from the central nervous system, despite prolonged distribution and terminal elimination from adipose tissue. In a small randomized trial, propofol facilitated successful intubation, reduced desaturation events, and had a shorter recovery time compared to a multi-agent approach [35]. However, response is highly variable, and adverse effects, such as clinically significant hypotension, are common [36, 37]. Propofol has also been used for less invasive surfactant administration with evidence of improved comfort, but was associated with increased need for respiratory support [38].

Ketamine, an NMDA antagonist with rapid onset of action (1-2 min) and relatively short duration (15-30 min), has also been studied. Pilot observational data in preterm neonates report lower pain scores and less vagal bradycardia compared to no premedication [39]. However, ketamine has direct negative inotropic effects. Although augmentation of cardiovascular function through stimulation of endogenous catecholamine release can generally overcome these effects, cardiac arrest has been reported in older patients with exhausted catecholamine stores [40]. The concerning adverse effect profiles of both propofol and ketamine support the use of remifentanil or fentanyl as standard of care prior to endotracheal intubation in neonates, with midazolam reserved for adjunctive sedation in neonates $\geq 34$ weeks postmenstrual age.

\section{Postoperative analgesia}

The optimal level of anesthesia and the specific pharmacologic approach for major surgery in neonates are an area of active investigation beyond the scope of this review [13]. Optimal pain management after major neonatal surgery is also essential. The mainstay of therapy for postoperative pain is an opioid, either as a continuous infusion or as scheduled bolus doses, for a duration that reflects the extent of the intervention [41]. Morphine $10 \mathrm{mcg} / \mathrm{kg} / \mathrm{h}$ or $30 \mathrm{mcg} /$ $\mathrm{kg} /$ dose every $3 \mathrm{~h}$ represent reasonable initial doses in opioid-naïve patients, with liberal bolus dosing provided as needed for breakthrough pain.

There is increasing interest in the use of spinal and epidural anesthesia for postoperative pain management in neonates. A large meta-analysis of preterm neonates clearly demonstrates decreased apnea and bradycardia in the postoperative period with epidural anesthesia, but failed to demonstrate a reduction in postoperative opioid use [42]. In contrast, scheduled intravenous acetaminophen effectively reduces postoperative opioid requirement [43]. The intravenous route is preferred over rectal therapy, because of erratic absorption and unclear efficacy for the latter [44, 45]. Despite the clear benefits of intravenous acetaminophen, its use has been restricted in some healthcare organizations due to relatively high cost. Therefore, intravenous acetaminophen should be restricted to evidence-based indications, including postoperative pain and not heel lance or eye examination [46].

\section{Sedation of the premature neonate during invasive mechanical ventilation}

Invasive mechanical ventilation is associated with significant distress in patients able to self-report [47]. For a neonatal population that cannot self-report, one must rely on indirect markers such as stress hormones [48], and must account for the detrimental effects of ventilator asynchrony, which can worsen chronic pulmonary disease through higher peak airway pressure and tidal volume [49]. Continuous analgesia or sedation should be avoided in preterm neonates undergoing short durations of invasive mechanical ventilation [50]. For prolonged invasive mechanical ventilation, nonpharmacologic therapy, including appropriate containment and an optimal sensory environment, is vital. Controversy exists regarding the role of continuous analgesia or sedation in preterm neonates requiring prolonged mechanical ventilation who exhibit agitation refractory to nonpharmacologic therapy (Tables 3 and 4).

\section{Opioids}

Although clinical trials of morphine or fentanyl for sedation of the chronically mechanically ventilated preterm neonate demonstrate no increase in the composite incidence of intraventricular hemorrhage, periventricular leukomalacia, or death (in the absence of pre-existing hypotension), they also show no benefit, with a longer duration of mechanical ventilation and delayed tolerance of enteral feedings [51-55]. Discrete brain injury aside, preclinical data are concerning, suggesting that prolonged opioid exposure may increase neuroapoptosis leading to neurodevelopmental deficits [56]. The neurodevelopmental risk of opioids may vary depending 
Table 3 Advantages and disadvantages of available agents for continuous sedation of preterm neonates during mechanical ventilation.

\begin{tabular}{lll}
\hline Agent & Advantages & Disadvantages \\
\hline Dexmedetomidine & - Decreased adjunctive sedation compared to fentanyl & - Potential hypotension and bradycardia \\
& - Decreased incidence of delirium compared to benzodiazepine & \\
& - Minimal respiratory depression & \\
& - Minimal impact on gastrointestinal motility & \\
Fentanyl & - Decreased adrenaline and cortisol concentrations & - Prolongation of mechanical ventilation \\
& - Less impact on gastrointestinal motility compared to morphine & - Delayed meconium passage \\
& & - Rapid tachyphylaxis \\
Midazolam & & - Increased severe IVH, PVL, or death \\
& & - Hypotension \\
& & - Myoclonus \\
& & - Frequent delirium \\
Morphine & - Increased ventilator synchrony & - Tachyphylaxis \\
& - Decreased adrenaline concentrations & - Hypotension \\
& - No impact on incidence of severe IVH, PVL, or death & - Prolongation of mechanical ventilation \\
& & - Prolongation of time to full enteral feedings \\
& & - Tachyphylaxis \\
\hline
\end{tabular}

$I V H$ intraventricular hemorrhage; $P V L$ periventricular leukomalacia.

Table 4 Early sedative/analgesic exposure and long-term outcome.

\begin{tabular}{|c|c|c|}
\hline Agent & Preclinical data & Clinical data \\
\hline Opioids & $\begin{array}{l}\text { - Neuroapoptosis } \\
\text { - Reduced neuronal density and dendritic length } \\
\text { - Reduced brain growth } \\
\text { - Persistently decreased motor activity } \\
\text { - Persistently impaired learning ability }\end{array}$ & $\begin{array}{l}\text { - Reduced cerebellar growth } \\
\text { - Increased muscle tone at } 36 \text { weeks postmenstrual age } \mathrm{a}^{\mathrm{a}} \\
\text { - Impaired cognitive and motor outcome at } 18 \text { months of age } \mathrm{e}^{\mathrm{a}} \\
\text { - Lower scores on the visual analysis domain of intelligence } \\
\text { quotient at } 5 \text { years of age } \\
\text { - Superior executive function by parent report at } 8-9 \text { years of age }\end{array}$ \\
\hline Benzodiazepines & $\begin{array}{l}\text { - Neuroapoptosis } \\
\text { - Suppressed neurogenesis } \\
\text { - Delayed motor development }\end{array}$ & - None \\
\hline $\begin{array}{l}\text { Alpha-2 } \\
\text { agonists }\end{array}$ & $\begin{array}{l}\text { - Neuroprotection and decreased lesion size in models of } \\
\text { periventricular leukomalacia } \\
\text { - Neuroprotection and improved developmental outcome } \\
\text { in models of hypoxia-ischemia and isoflurane exposure }\end{array}$ & - None \\
\hline
\end{tabular}

${ }^{a}$ Retrospective and prospective studies of relatively high-level opioid exposure.

${ }^{b}$ Prospective study of relatively low-level opioid exposure.

on the agent used and the degree of prematurity, possibly resulting from impaired brain growth rather than catastrophic insult.

Continuous infusion of fentanyl at standard doses in preterm neonates results in significant accumulation of drug [57]. A retrospective cohort study demonstrated that cerebellar growth decreases as cumulative fentanyl exposure increases [58]. Further, fentanyl administered as a $1-\mathrm{mcg} / \mathrm{kg}$ bolus followed by $1 \mathrm{mcg} / \mathrm{kg} / \mathrm{h}$ continuous infusion for 7 days or less (median duration of exposure in the treatment group was $151.5 \mathrm{~h}$ ) has been associated with neurodevelopmental impairment at 24 months corrected age [55, 59]. A recent, robust pharmacokinetic study of continuous infusion fentanyl suggests alternative dosing for preterm neonates born at $<32$ weeks gestational age $(0.5 \mathrm{mcg} / \mathrm{kg} / \mathrm{h}$ for the first 4 days of life and $0.75 \mathrm{mcg} / \mathrm{kg} / \mathrm{h}$ from day of life 5-9) [60]. This approach has the potential to mitigate some of the negative neurodevelopmental consequences of fentanyl exposure, although it requires prospective evaluation with long-term follow-up.

Human studies of morphine have been slightly more reassuring; morphine $100-\mathrm{mcg} / \mathrm{kg}$ bolus followed by $10 \mathrm{mcg} / \mathrm{kg} / \mathrm{h}$ continuous infusion for 7 days or less (median duration of exposure in the treatment group was $77 \mathrm{~h}$ ) showed no detrimental long-term neurological effects [54, 61, 62]. However, retrospective data clearly highlight the importance of limiting cumulative dose to optimize brain growth and long-term outcome [63-65].

\section{Benzodiazepines}

Benzodiazepines are a drug class that should be avoided in mechanically ventilated preterm neonates due to substantial risk of severe intraventricular hemorrhage, periventricular 
leukomalacia, or death [66]. These acute adverse effects may be driven by transient hypotension and decreased mean cerebral blood flow velocity associated with bolus doses in preterm neonates [34]. Preclinical studies have also shown neuroapoptosis and long-term functional deficits following early benzodiazepine exposure [56]. Given the availability of other options, current evidence supports avoidance of benzodiazepines in preterm neonates.

\section{Alpha-2 receptor agonists}

Dexmedetomidine, a highly selective alpha-2-adrenergic receptor agonist that provides analgesia, anxiolysis, and sedation, has the potential to augment or replace opioids and benzodiazepines in chronically mechanically ventilated preterm neonates. Clinical data in preterm neonates suggest superior efficacy compared to opioids [67]. Further, dexmedetomidine does not cause respiratory depression or gastrointestinal dysmotility. Preclinical data regarding alpha-2 agonists also suggest the possibility of neuroprotection of the immature brain [68]. Robust safety and efficacy data are needed in preterm neonates before universal usage can be recommended, but incorporation of dexmedetomidine into sedation protocols for preterm neonates may be warranted given the clear adverse effects of opioids and benzodiazepines.

\section{Sedation of the term neonate during invasive mechanical ventilation}

In contrast to preterm neonates, severe illness in late preterm or term neonates often warrants continuous infusion of multimodal analgesia and sedation [50]. Reduction of left ventricular afterload, achievement of ventilator synchrony, and reduction of total metabolic demand are mainstays of treatment for respiratory failure often complicated by pulmonary hypertension. In addition to differences in physiology, the duration of analgesia and sedation should be significantly shorter for term neonates compared to preterm neonates.

In mechanically ventilated term neonates, there are no clear data to guide specific sedative/analgesic choices. A multimodal approach has the potential to reduce the dosage of any individual agent and mitigate the overall risk of adverse effects [69]. Fentanyl or morphine in conjunction with midazolam achieve this desired outcome. Some clinicians may prefer fentanyl due to a more rapid onset and shorter duration of action, although clearance is substantially prolonged in critically ill term neonates compared to older pediatric patients [70]. Morphine or hydromorphone may be preferred in neonates who require extracorporeal membrane oxygenation due to significant sequestration of fentanyl by the circuit; sequestration of lorazepam and midazolam must also be considered in this population [71]. Dexmedetomidine may also play a role, providing sedation without additive respiratory depression [72]. However, the benefits of dexmedetomidine in term neonates requiring continuous sedation from opioids and benzodiazepines are likely to be modest [73]. Regardless of the specific cocktail, titration should be based on sedation scale scores and the duration of therapy should be limited to the duration of acute lung disease.

\section{Addressing tolerance and avoiding withdrawal}

\section{Tolerance}

Despite efforts to minimize the dose and duration of sedation and analgesia, preterm and term neonates with prolonged ventilator dependence may require prolonged exposure to opioids, benzodiazepines, and/or alpha-2 agonists. Drug tolerance, or tachyphylaxis, increases the neonate's dosing requirement often without improved clinical efficacy [74]. A limited number of strategies exist to combat tachyphylaxis in neonates.

Opioid rotation may be utilized to maximize benefit while mitigating the risk of further dose escalation and potential consequent adverse effects [75]. Limited data guide opioid rotation in adult patients; standards of care in neonates have been established exclusively by extrapolation from adult literature considering the unique pharmacokinetic properties of opioids in the neonatal population (Table 5) [76]. Although standard of care in pediatric palliative care, the appropriateness of these approaches requires careful validation in neonates.

Clinicians may also consider alternative medications when neonates experience agitation resistant to current standards of care. Methadone has been utilized as an alternative or adjunctive opioid with the additional advantage of NMDA receptor antagonism and delta-opiate desensitization. Dosing, safety, and efficacy have been established for the treatment of neonatal abstinence syndrome [77]. Despite long-standing consideration, minimal data exist regarding dosing and efficacy in the setting of chronic neonatal pain [78]. Clinicians utilizing this therapy must monitor carefully for adverse effects, including QTc interval prolongation [79].

Gabapentin has emerged as a potential treatment option for visceral hyperalgesia refractory to conventional therapies. Infants with a history of gastrointestinal morbidity with or without concomitant neurologic conditions may be suffering from visceral hyperalgesia if they demonstrate irritability, hypertonicity, and/or feeding intolerance without 
Table 5 Approach to opioid rotation in the neonate.

\begin{tabular}{llll}
\hline Current agent & Arbitrary maximum dose & New agent & Dose calculation \\
\hline Fentanyl & $5 \mathrm{mcg} / \mathrm{kg} / \mathrm{h}$ & Morphine $(\mathrm{mcg} / \mathrm{kg} / \mathrm{hr})$ & $\begin{array}{l}\text { Multiply fentanyl dose by } 10-20 \text { and reduce by } \sim 25 \% \text { for cross } \\
\text { tolerance }\end{array}$ \\
Morphine & $200 \mathrm{mcg} / \mathrm{kg} / \mathrm{h}$ & Hydromorphone $(\mathrm{mcg} / \mathrm{kg} / \mathrm{hr})$ & Divide morphine dose by 7 and reduce by $\sim 25 \%$ for cross tolerance \\
\hline
\end{tabular}

Table 6 Intravenous to oral analgesic/sedation conversions.

\begin{tabular}{lll}
\hline Current intravenous agent & Oral alternative & Dose calculation \\
\hline Fentanyl $(\mathrm{mcg} / \mathrm{kg} / \mathrm{h})$ & Morphine $(\mathrm{mg} / \mathrm{kg} / \mathrm{dose})^{\mathrm{a}}$ & Multiply hourly fentanyl dose by 0.1. Administer as morphine every 4h. \\
Fentanyl $(\mathrm{mcg} / \mathrm{kg} / \mathrm{h})$ & Methadone $(\mathrm{mg} / \mathrm{kg} / \mathrm{dose})^{\mathrm{a}}$ & Multiply hourly fentanyl dose by 0.05-0.1. Administer as methadone every 6h. \\
Midazolam $(\mathrm{mg} / \mathrm{kg} / \mathrm{h})$ & Lorazepam $(\mathrm{mg} / \mathrm{kg} / \mathrm{dose})^{\mathrm{a}}$ & Multiply hourly midazolam dose by 0.5-1. Administer as lorazepam every 6 h. \\
Dexmedetomidine $(\mathrm{mcg} / \mathrm{kg} / \mathrm{h})$ & Clonidine $(\mathrm{mcg} / \mathrm{kg} / \mathrm{dose})^{\mathrm{a}}$ & Multiply hourly dexmedetomidine dose by 5 . Administer as clonidine every 4 h. \\
\hline
\end{tabular}

${ }^{\mathrm{a}}$ Dose calculations result in weight-based dose. Multiply by dosing weight to convert from $\mathrm{mg} / \mathrm{kg} / \mathrm{dose}$ to $\mathrm{mg} / \mathrm{dose}$.

a clear etiology after diagnostic evaluation. In these infants, gabapentin has the potential to decrease irritability, improve oral feeding fraction, and/or decrease cardiorespiratory events [80]. It is critical to determine the goals of therapy prior to initiation of this experimental agent and utilize objective criteria for therapeutic success including a validated sedation scale. Infants who receive gabapentin should be monitored carefully for bradycardia and nystagmus. Prospective trials are urgently needed to evaluate the benefits and risks of gabapentin compared to current standards of care, with a specific focus on long-term developmental outcomes.

\section{latrogenic withdrawal}

Prolonged pharmacologic treatment of pain and agitation will produce iatrogenic drug dependence. Cumulative exposure, or the combination of total dose and consecutive days of therapy, correlate with the likelihood of withdrawal symptoms [81]. However, the frequency of tolerance and withdrawal also varies based on differing chemical structures (e.g., synthetic opioids > opiates), biological half-lives, and interactions with neuronal protein-kinases (e.g., fentanyl $>$ morphine $>$ methadone) [82]. Well-designed collaborative studies of patients with neonatal abstinence syndrome have advanced knowledge of neonatal drug withdrawal; however, limited evidence informs the specific approach to treating iatrogenic withdrawal [83].

Neonates with ongoing requirement for intravenous access for parenteral nutrition or other pharmacotherapy may be weaned gradually from their continuous opioid, benzodiazepine, or alpha-2-agonist infusion. Controversy exists regarding the appropriate duration of analgesic and sedation weans. Limited research suggests efficacy with relatively short weans (5-10 days), regardless of duration of exposure. Some experts argue instead for a wean duration proportional to the duration of continuous exposure, with customized weans generally equivalent in duration to relatively short exposures ( $\leq 1$ month) and at least half the duration of prolonged exposures ( $>1$ month) [83]. For neonates who no longer require intravenous access, oral agents may be utilized to complete weans (Table 6). Neonatal units must weigh the risks and benefits of utilizing the same assessment tool for neonatal abstinence and iatrogenic withdrawal versus introducing a tool validated for iatrogenic withdrawal in older pediatric patients [83]. Centers with robust experience in preventing iatrogenic drug withdrawal should strongly consider evaluation and publication of their methodology and outcomes to add evidence to this largely anecdotal aspect of care.

\section{Sedation of the term neonate during therapeutic hypothermia}

Therapeutic hypothermia $(\mathrm{TH})$ has become standard of care for neonates with hypoxic-ischemic encephalopathy, but is associated with significant physiologic stress to the neonate, as evidenced by elevated circulating cortisol and norepinephrine levels when compared to neonates maintained at normothermia [84]. The impact of this stress may be sufficient to negate the neurodevelopmental benefits of TH, a hypothesis supported by preclinical neonatal models [85]. Excessive exposure to endogenous cortisol and shivering during unsedated cooling have been proposed as mechanisms. The negative effects of shivering are blunted by continuous infusion of concurrent analgesia (remifentanil) and sedation (propofol) in a preclinical model [86]. However, these findings may not extrapolate to human neonates, who preferentially generate heat through utilization of brown fat rather than shivering, in contrast to piglets who lack brown fat [87]. Therefore, the neonate's clinical status 
and the benefit-risk profile of pharmacologic agents should be considered in decision-making regarding analgesia or sedation for neonates undergoing $\mathrm{TH}$.

\section{Opioids during TH}

A retrospective study of asphyxiated neonates published prior to the widespread use of TH-identified less brain injury and better scores on the Pediatric Cerebral Performance Category Scale at discharge in neonates who received morphine compared to those who did not, despite greater severity of illness [88]. While randomized controlled trials of TH allowed analgesia/sedation at the providers' discretion, only the neo.nEURO study used standardized opioid treatment (morphine $0.1 \mathrm{mg} / \mathrm{kg}$ every $4 \mathrm{~h}$ or an equivalent dose of fentanyl) $[89,90]$. This trial identified a larger effect size of TH ( $32 \%$ absolute risk reduction [ARR] of death or severe disability) compared to previous trials $(\mathrm{ARR}=15 \%)$, which the authors asserted may have been partially due to consistent use of opioid analgesia. However, the relatively high incidence of death or severe disability in the control group of this trial may also have contributed to effect size differences. In addition, increased patient comfort with servo-controlled cooling devices (as opposed to manually controlled devices) may modify the clinical benefit of pharmacologic analgesia/sedation.

When choosing to provide opioids during $\mathrm{TH}$, one must consider the risk of adverse effects and account for the altered physiology of hypothermia and its impact on drug accumulation. Retrospective analysis of the NICHD TH trial revealed a longer duration of mechanical ventilation, time to full oral feedings, and length of stay associated with open-label sedation/analgesic exposure (opioids, benzodiazepines, and barbiturates) [91]. Morphine clearance is altered during $\mathrm{TH}$ through at least three mechanisms: decreased activity of cytochrome P450 enzymes, reduced volume of distribution from peripheral vasoconstriction, and reduced glucuronidation [92]. Hepatic and renal injury, which are variable and often not immediately appreciated after asphyxia, provide additional impediments to drug clearance. If morphine is utilized for sedation during therapeutic hypothermia, clinicians should maintain strict adherence to a treatment protocol designed for TH to limit the risk of adverse events. Unlike the use of morphine in critically ill term neonates where frequent assessment and dose adjustment is the ideal approach, clinicians should avoid titration of the continuous infusion outside of extreme clinical circumstances; it will not produce acute clinical benefits, but will result in a higher plateau concentration after accumulation and increase risk of adverse events. Two recent large pharmacokinetic studies have been conducted that suggest morphine $50 \mathrm{mcg} / \mathrm{kg}$ intravenously once, followed by $5 \mathrm{mcg} / \mathrm{kg} / \mathrm{h}$ is appropriate dosing to maintain therapeutic concentrations during TH $[92,93]$. Acute agitation or shivering should be managed through conservative bolus dosing (generally $50 \mathrm{mcg} / \mathrm{kg}$ ) with careful clinical assessment before and after the dose.

\section{An alternative approach-dexmedetomidine}

Following a hypoxic insult, noradrenaline-mediated activation of alpha-2-adrenergic receptors appears to suppress brain activity during the latent phase of hypoxic-ischemic encephalopathy. Blockade of alpha-2-adrenergic receptors inhibits this suppression and exacerbates neuronal loss, while low-dose infusion of an exogenous alpha-2adrenergic receptor agonist is neuroprotective [94]. Dexmedetomidine increases expression of enzymes responsible for neuronal survival and synaptic plasticity and suppresses cytokine-mediated brain injury [95]. In animal models, treatment with dexmedetomidine after hypoxia-ischemia reduces loss of brain tissue and improves neurologic function [96]. Importantly, the neuroprotective effects of dexmedetomidine in these models are comparable, but not additive, to those achieved with TH [97]. Clinically, alpha-2 agonists lower the shivering threshold to a similar degree as general anesthetics, while providing moderate sedation and no respiratory depression [98].

Extrapolation of preclinical data to neonates undergoing TH must be done with caution. Pediatric patients placed on dexmedetomidine infusion after hypoxic-ischemic events often experience significant bradycardia [99]. As the most common side effect of $\mathrm{TH}$ is bradycardia, the additive effect raises the theoretical possibility of bradyarrhythmia or inadequate cardiac output. Like morphine, the pharmacokinetics of dexmedetomidine are altered such that clearance is reduced by $56 \%$ following experimental hypoxiaischemia and an additional 33\% during TH [100]. A retrospective cohort study identified an effective dose of $0.3 \mathrm{mcg} / \mathrm{kg} / \mathrm{h}$ (range $0.2-0.5 \mathrm{mcg} / \mathrm{kg} / \mathrm{h}$ ) during TH with no evidence of altered respiratory status, bradycardia, or hypotension at these lower doses [101]. Further, full enteral feedings were achieved at a mean of 6 days of life, sooner than historic controls treated with fentanyl infusion. Prospective trials are needed to confirm the favorable benefit-risk profile of dexmedetomidine in $\mathrm{TH}$ and evaluate implications for long-term neurodevelopment, but in the interim, this appears to be an appealing alternative to morphine in neonates requiring sedation during $\mathrm{TH}$.

\section{Conclusions}

Critically ill neonates are exposed to frequent painful procedures and agitating stimuli, with a negative impact on long-term outcome in the most vulnerable patients. Despite 
extensive research, the optimal approach to assessment, nonpharmacologic care, and pharmacotherapy remains elusive in most circumstances. Investigators must prioritize study designs that ethically generate novel data, ideally in collaboration with regulatory agencies to reduce the exclusively off-label utilization of medications discussed in this review. Even in the absence of scientific consensus, neonatal units must develop algorithms for the avoidance and treatment of pain and agitation in common clinical situations. Strong consideration should be given to the short-term and long-term safety of available interventions in the setting of limited data regarding objective efficacy. Existing analgesia or sedation practices should be maintained only where sufficient historic data support that standard. In the absence of data supporting efficacy, safety, and long-term benefit, novel interventions should be strongly considered in current clinical practice.

Funding National Institutes of Health/National Institute of Neurological Disorders and Stroke K23 NS111086 (awarded to ZV) and National Institutes of Health/National Heart, Lung, and Blood Institute K23 HL141602 (awarded to CMO).

\section{Compliance with ethical standards}

Conflict of interest The authors declare that they have no conflict of interest.

Publisher's note Springer Nature remains neutral with regard to jurisdictional claims in published maps and institutional affiliations.

\section{References}

1. Anand KJ. Clinical importance of pain and stress in preterm neonates. Biol Neonate. 1998;73:1-9.

2. Anand KJ, Hickey PR. Pain and its effects in the human neonate and fetus. N Engl J Med. 1987;317:1321-9.

3. Anand KJ, Sippell WG, Aynsley-Green A. Randomised trial of fentanyl anaesthesia in preterm babies undergoing surgery: effects on the stress response. Lancet. 1987;1:62-6.

4. Brummelte S, Grunau RE, Chau V, Poskitt KJ, Brant R, Vinall J, et al. Procedural pain and brain development in premature newborns. Ann Neurol. 2012;71:385-96.

5. Chau CMY, Ranger M, Bichin M, Park MTM, Amaral RSC, Chakravarty $\mathrm{M}$, et al. Hippocampus, amygdala, and thalamus volumes in very preterm children at 8 years: neonatal pain and genetic variation. Front Behav Neurosci. 2019;13:51.

6. Anand KJS. Defining pain in newborns: need for a uniform taxonomy? Acta Paediatrica. 2017;106:1438-44.

7. Kappesser J, Kamper-Fuhrmann E, de Laffolie J, Faas D, Ehrhardt H, Franck LS, et al. Pain-specific reactions or indicators of a general stress response?: Investigating the discriminant validity of 5 well-established neonatal pain assessment tools. Clin J Pain. 2019:35:101-10.

8. Hummel P, Puchalski M, Creech SD, Weiss MG. Clinical reliability and validity of the N-PASS: neonatal pain, agitation and sedation scale with prolonged pain. J Perinatol. 2008;28:55-60

9. Benoit B, Martin-Misener R, Newman A, Latimer M, CampbellYeo M. Neurophysiological assessment of acute pain in infants: a scoping review of research methods. Acta Paediatrica. 2017;106:1053-66.

10. Jansen J, Beijers R, Riksen-Walraven M, de Weerth C. Cortisol reactivity in young infants. Psychoneuroendocrinology. 2010;35:329-38.

11. Roue JM, Rioualen S, Gendras J, Misery L, Gouillou M, Sizun J. Multi-modal pain assessment: are near-infrared spectroscopy, skin conductance, salivary cortisol, physiologic parameters, and Neonatal Facial Coding System interrelated during venepuncture in healthy, term neonates? J Pain Res. 2018;11:2257-67.

12. Lin JC, Strauss RG, Kulhavy JC, Johnson KJ, Zimmerman MB, Cress GA, et al. Phlebotomy overdraw in the neonatal intensive care nursery. Pediatrics 2000;106:E19.

13. Disma N, O'Leary JD, Loepke AW, Brambrink AM, Becke K, Clausen NG, et al. Anesthesia and the developing brain: a way forward for laboratory and clinical research. Paediatr Anaesth. 2018;28:758-63.

14. Committee on Fetus and Newborn, Section on Anesthesiology and Pain Medicine. Prevention and management of procedural pain in the neonate: an update. Pediatrics. 2016;137:e20154271.

15. Hatfield LA, Murphy N, Karp K, Polomano RC. A systematic review of behavioral and environmental interventions for procedural pain management in preterm infants. J Pediatr Nurs. 2019;44:22-30.

16. Pillai Riddell RR, Racine NM, Gennis HG, Turcotte K, Uman LS, Horton RE, et al. Non-pharmacological management of infant and young child procedural pain. Cochrane Database Syst Rev. 2015:CD006275.

17. Stevens B, Yamada J, Ohlsson A, Haliburton S, Shorkey A. Sucrose for analgesia in newborn infants undergoing painful procedures. Cochrane Database Syst Rev. 2016;7:CD001069.

18. Schneider J, Duerden EG, Guo T, Ng K, Hagmann P, Bickle Graz M, et al. Procedural pain and oral glucose in preterm neonates: brain development and sex-specific effects. Pain. 2018;159:515-25.

19. McPherson C, Grunau RE. Neonatal pain control and neurologic effects of anesthetics and sedatives in preterm infants. Clin Perinatol. 2014;41:209-27.

20. Johnston CC, Filion F, Snider L, Majnemer A, Limperopoulos C, Walker CD, et al. Routine sucrose analgesia during the first week of life in neonates younger than 31 weeks' postconceptional age. Pediatrics. 2002;110:523-8.

21. Stevens B, Yamada J, Campbell-Yeo M, Gibbins S, Harrison D, Dionne K, et al. The minimally effective dose of sucrose for procedural pain relief in neonates: a randomized controlled trial. BMC Pediatrics. 2018;18:85.

22. Kelly MA, Finer NN. Nasotracheal intubation in the neonate: physiologic responses and effects of atropine and pancuronium. $\mathrm{J}$ Pediatr. 1984;105:303-9.

23. Kumar P, Denson SE, Mancuso TJ, Committee on Fetus and Newborn, Section on Anesthesiology and Pain Medicine. Premedication for nonemergency endotracheal intubation in the neonate. Pediatrics. 2010;125:608-15.

24. Le CN, Garey DM, Leone TA, Goodmar JK, Rich W, Finer NN. Impact of premedication on neonatal intubations by pediatric and neonatal trainees. J Perinatol. 2014;34:458-60.

25. Pereira e Silva Y, Gomez RS, Marcatto JdeO, Maximo TA, Barbosa RF, Simoes e Silva AC. Morphine versus remifentanil for intubating preterm neonates. Arch Dis Child Fetal Neonatal Ed. 2007;92:F293-4.

26. Elmekkawi A, Abdelgadir D, Van Dyk J, Choudhury J, Dunn M. Use of naloxone to minimize extubation failure after premedication for INSURE procedure in preterm neonates. J Neonatal Perinat Med. 2016;9:363-70.

27. McCluskey SV, Graner KK, Kemp J, Aloumanis V, Ben M, Kupiec T, et al. Stability of fentanyl $5 \mathrm{microg} / \mathrm{mL}$ diluted with 
$0.9 \%$ sodium chloride injection and stored in polypropylene syringes. Am J Health Syst Pharm. 2009;66:860-3.

28. de Kort EH, Hanff LM, Roofthooft D, Reiss IK, Simons SH. Insufficient sedation and severe side effects after fast administration of Remifentanil during INSURE in preterm newborns. Neonatology. 2017;111:172-6.

29. Hippard HK, Govindan K, Friedman EM, Sulek M, Giannoni C, Larrier D, et al. Postoperative analgesic and behavioral effects of intranasal fentanyl, intravenous morphine, and intramuscular morphine in pediatric patients undergoing bilateral myringotomy and placement of ventilating tubes. Anesth Analg. 2012;115:356-63.

30. Yao Y, Ni J, Yang Y, Guo Y, Ye H, Chen Y. The optimum dose of intranasal remifentanil for laryngeal mask airway insertion during sevoflurane induction in children: a randomized controlled trial. Int J Clin Exp Med. 2015;8:21235-40.

31. Caldwell CD, Watterberg KL. Effect of premedication regimen on infant pain and stress response to endotracheal intubation. J Perinatol. 2015;35:415-8.

32. Milesi C, Baleine J, Mura T, Benito-Castro F, Ferragu F, Thiriez $\mathrm{G}$, et al. Nasal midazolam vs ketamine for neonatal intubation in the delivery room: a randomised trial. Arch Dis Child Fetal Neonatal Ed. 2018;103:F221-6.

33. Attardi DM, Paul DA, Tuttle DJ, Greenspan JS. Premedication for intubation in neonates. Arch Dis Child Fetal Neonatal Ed. 2000;83:F161.

34. van Straaten HL, Rademaker CM, de Vries LS. Comparison of the effect of midazolam or vecuronium on blood pressure and cerebral blood flow velocity in the premature newborn. Dev Pharmacol Ther. 1992;19:191-5.

35. Ghanta S, Abdel-Latif ME, Lui K, Ravindranathan H, Awad J, Oei J. Propofol compared with the morphine, atropine, and suxamethonium regimen as induction agents for neonatal endotracheal intubation: a randomized, controlled trial. Pediatrics. 2007;119:e1248-55.

36. Smits A, Thewissen L, Caicedo A, Naulaers G, Allegaert K. Propofol dose-finding to reach optimal effect for (Semi-)elective intubation in neonates. J Pediatr. 2016;179:54-60.e9.

37. Simons SH, van der Lee R, Reiss IK, van Weissenbruch MM. Clinical evaluation of propofol as sedative for endotracheal intubation in neonates. Acta Paediatrica. 2013;102: e487-92.

38. Dekker J, Lopriore E, van Zanten HA, Tan R, Hooper SB, Te Pas $\mathrm{AB}$, et al. Sedation during minimal invasive surfactant therapy: a randomised controlled trial. Arch Dis Child Fetal Neonatal Ed. 2019;104:F378-83.

39. Barois J, Tourneux P. Ketamine and atropine decrease pain for preterm newborn tracheal intubation in the delivery room: an observational pilot study. Acta Paediatrica. 2013;102:e534-8.

40. Dewhirst E, Frazier WJ, Leder M, Fraser DD, Tobias JD. Cardiac arrest following ketamine administration for rapid sequence intubation. J Intensive Care Med. 2013;28:375-9.

41. Bouwmeester NJ, Anand KJ, van Dijk M, Hop WC, Boomsma F, Tibboel D. Hormonal and metabolic stress responses after major surgery in children aged 0-3 years: a double-blind, randomized trial comparing the effects of continuous versus intermittent morphine. Br J Anaesth. 2001;87:390-9.

42. Jones LJ, Craven PD, Lakkundi A, Foster JP, Badawi N. Regional (spinal, epidural, caudal) versus general anaesthesia in preterm infants undergoing inguinal herniorrhaphy in early infancy. Cochrane Database Syst Rev. 2015:CD003669.

43. Ceelie I, de Wildt SN, van Dijk M, van den Berg MM, van den Bosch GE, Duivenvoorden HJ, et al. Effect of intravenous paracetamol on postoperative morphine requirements in neonates and infants undergoing major noncardiac surgery: a randomized controlled trial. JAMA. 2013;309:149-54.
44. Lin YC, Sussman HH, Benitz WE. Plasma concentrations after rectal administration of acetaminophen in preterm neonates. Paediatr Anaesth. 1997;7:457-9.

45. van der Marel CD, Peters JW, Bouwmeester NJ, Jacqz-Aigrain E, van den Anker JN, Tibboel D. Rectal acetaminophen does not reduce morphine consumption after major surgery in young infants. Br J Anaesth. 2007;98:372-9.

46. Ohlsson A, Shah PS. Paracetamol (acetaminophen) for prevention or treatment of pain in newborns. Cochrane Database Syst Rev. 2016;10:CD011219.

47. Gelinas C, Fortier M, Viens C, Fillion L, Puntillo K. Pain assessment and management in critically ill intubated patients: a retrospective study. Am J Crit Care. 2004;13:126-35.

48. Quinn MW, de Boer RC, Ansari N, Baumer JH. Stress response and mode of ventilation in preterm infants. Arch Dis Child Fetal Neonatal Ed. 1998;78:F195-8.

49. Longhini F, Ferrero F, De Luca D, Cosi G, Alemani M, Colombo $\mathrm{D}$, et al. Neurally adjusted ventilatory assist in preterm neonates with acute respiratory failure. Neonatology. 2015;107:60-7.

50. Ancora G, Lago P, Garetti E, Merazzi D, Savant Levet P, Bellieni $\mathrm{CV}$, et al. Evidence-based clinical guidelines on analgesia and sedation in newborn infants undergoing assisted ventilation and endotracheal intubation. Acta Paediatrica. 2019;108:208-17.

51. Anand KJ, Hall RW, Desai N, Shephard B, Bergqvist LL, Young TE, et al. Effects of morphine analgesia in ventilated preterm neonates: primary outcomes from the NEOPAIN randomised trial. Lancet 2004;363:1673-82.

52. Bhandari V, Bergqvist LL, Kronsberg SS, Barton BA, Anand KJ. Morphine administration and short-term pulmonary outcomes among ventilated preterm infants. Pediatrics. 2005;116:352-9.

53. Menon G, Boyle EM, Bergqvist LL, McIntosh N, Barton BA, Anand KJ. Morphine analgesia and gastrointestinal morbidity in preterm infants: secondary results from the NEOPAIN trial. Arch Dis Child Fetal Neonatal Ed. 2008;93:F362-7.

54. Simons SH, van Dijk M, van Lingen RA, Roofthooft D, Duivenvoorden $\mathrm{HJ}$, Jongeneel $\mathrm{N}$, et al. Routine morphine infusion in preterm newborns who received ventilatory support: a randomized controlled trial. JAMA. 2003;290:2419-27.

55. Ancora G, Lago P, Garetti E, Pirelli A, Merazzi D, Mastrocola $M$, et al. Efficacy and safety of continuous infusion of fentanyl for pain control in preterm newborns on mechanical ventilation. $\mathbf{J}$ Pediatr. 2013;163:645-51.e1.

56. Durrmeyer X, Vutskits L, Anand KJ, Rimensberger PC. Use of analgesic and sedative drugs in the NICU: integrating clinical trials and laboratory data. Pediatr Res. 2010;67:117-27.

57. Saarenmaa E, Neuvonen PJ, Fellman V. Gestational age and birth weight effects on plasma clearance of fentanyl in newborn infants. J Pediatr. 2000;136:767-70.

58. McPherson C, Haslam M, Pineda R, Rogers C, Neil JJ, Inder TE. Brain injury and development in preterm infants exposed to fentanyl. Ann Pharmacother. 2015;49:1291-7.

59. Ancora G, Lago P, Garetti E, Pirelli A, Merazzi D, Pierantoni L, et al. Follow-up at the corrected age of 24 months of preterm newborns receiving continuous infusion of fentanyl for pain control during mechanical ventilation. Pain. 2017;158:840-5.

60. Völler S, Flint RB, Andriessen P, Allegaert K, Zimmermann LJI, Liem KD, et al. Rapidly maturing fentanyl clearance in preterm neonates. Arch Dis Child Fetal Neonatal Ed. 2019;104:F598-603.

61. de Graaf J, van Lingen RA, Simons SH, Anand KJ, Duivenvoorden $\mathrm{HJ}$, Weisglas-Kuperus N, et al. Long-term effects of routine morphine infusion in mechanically ventilated neonates on children's functioning: five-year follow-up of a randomized controlled trial. Pain. 2011;152:1391-7.

62. de Graaf J, van Lingen RA, Valkenburg AJ, Weisglas-Kuperus N, Groot Jebbink L, Wijnberg-Williams B, et al. Does neonatal 
morphine use affect neuropsychological outcomes at 8 to 9 years of age? Pain. 2013;154:449-58.

63. Steinhorn R, McPherson C, Anderson PJ, Neil J, Doyle LW, Inder T. Neonatal morphine exposure in very preterm infantscerebral development and outcomes. J Pediatr. 2015;166:1200-7.e4

64. Zwicker JG, Miller SP, Grunau RE, Chau V, Brant R, Studholme $\mathrm{C}$, et al. Smaller cerebellar growth and poorer neurodevelopmental outcomes in very preterm infants exposed to neonatal morphine. J Pediatr. 2016;172:81-7.e2.

65. Chau CMY, Ross CJD, Chau V, Synnes AR, Miller SP, Carleton $\mathrm{B}$, et al. Morphine biotransformation genes and neonatal clinical factors predicted behaviour problems in very preterm children at 18months. EBioMedicine. 2019;40:655-62.

66. Anand KJ, Barton BA, McIntosh N, Lagercrantz H, Pelausa E, Young TE, et al. Analgesia and sedation in preterm neonates who require ventilatory support: results from the NOPAIN trial. Neonatal outcome and prolonged analgesia in neonates. Arch Pediatr Adolesc Med. 1999;153:331-8.

67. O'Mara K, Gal P, Wimmer J, Ransom JL, Carlos RQ, Dimaguila MA, et al. Dexmedetomidine versus standard therapy with fentanyl for sedation in mechanically ventilated premature neonates. J Pediatr Pharmacol Ther. 2012;17:252-62.

68. Laudenbach V, Mantz J, Lagercrantz H, Desmonts JM, Evrard P, Gressens P. Effects of alpha(2)-adrenoceptor agonists on perinatal excitotoxic brain injury: comparison of clonidine and dexmedetomidine. Anesthesiology. 2002;96:134-41.

69. Lovich-Sapola J, Smith CE, Brandt CP. Postoperative pain control. Surg Clin North Am. 2015;95:301-18.

70. Ziesenitz VC, Vaughns JD, Koch G, Mikus G, van den Anker JN. Pharmacokinetics of fentanyl and its derivatives in children: a comprehensive review. Clin Pharmacokinet. 2018;57:125-49.

71. Harthan AA, Buckley KW, Heger ML, Fortuna RS, Mays K. Medication adsorption into contemporary extracorporeal membrane oxygenator circuits. J Pediatr Pharmacol Ther. 2014;19:288-95.

72. Su F, Nicolson SC, Zuppa AF. A dose-response study of dexmedetomidine administered as the primary sedative in infants following open heart surgery. Pediatr Crit Care Med. 2013;14:499-507.

73. Garisto C, Ricci Z, Tofani L, Benegni S, Pezzella C, Cogo P. Use of low-dose dexmedetomidine in combination with opioids and midazolam in pediatric cardiac surgical patients: randomized controlled trial. Minerva Anestesiol. 2018;84:1053-62.

74. Arnold JH, Truog RD, Scavone JM, Fenton T. Changes in the pharmacodynamic response to fentanyl in neonates during continuous infusion. J Pediatr. 1991;119:639-43.

75. Fine PG, Portenoy RK. Ad hoc expert panel on evidence review and guidelines for opioid rotation. Establishing "best practices" for opioid rotation: conclusions of an expert panel. J Pain Symptom Manag. 2009;38:418-25.

76. McPherson ML. Why equianalgesic tables are only part of the answer to equianalgesia. Ann Palliat Med. 2020;9:537-41.

77. Davis JM, Shenberger J, Terrin N, Breeze JL, Hudak M, Wachman EM, et al. Comparison of safety and efficacy of methadone vs morphine for treatment of neonatal abstinence syndrome: a randomized clinical trial. JAMA Pediatr. 2018;172:741-8.

78. Chana SK, Anand KJ. Can we use methadone for analgesia in neonates? Arch Dis Child Fetal Neonatal Ed. 2001;85: F79-81.

79. Parikh R, Hussain T, Holder G, Bhoyar A, Ewer AK. Maternal methadone therapy increases QTc interval in newborn infants. Arch Dis Child Fetal Neonatal Ed. 2011;96:F141-3.

80. Burnsed JC, Heinan K, Letzkus L, Zanelli S. Gabapentin for pain, movement disorders, and irritability in neonates and infants. Dev Med Child Neurol 2020;62:386-9.
81. Dominguez KD, Lomako DM, Katz RW, Kelly HW. Opioid withdrawal in critically ill neonates. Ann Pharmacother. 2003;37:473-7.

82. Anand KJ, Willson DF, Berger J, Harrison R, Meert KL, Zimmerman $\mathrm{J}$, et al. Tolerance and withdrawal from prolonged opioid use in critically ill children. Pediatrics 2010;125: e1208-25.

83. Hudak ML, Tan RC. Committee on Drugs, Committee on Fetus and Newborn, American Academy of Pediatrics. Neonatal drug withdrawal. Pediatrics 2012;129:e540-60.

84. Davidson JO, Fraser M, Naylor AS, Roelfsema V, Gunn AJ, Bennet L. Effect of cerebral hypothermia on cortisol and adrenocorticotropic hormone responses after umbilical cord occlusion in preterm fetal sheep. Pediatr Res. 2008;63:51-5.

85. Thoresen M, Satas S, Loberg EM, Whitelaw A, Acolet D, Lindgren $\mathrm{C}$, et al. Twenty-four hours of mild hypothermia in unsedated newborn pigs starting after a severe global hypoxicischemic insult is not neuroprotective. Pediatr Res. 2001;50:405-11.

86. Chakkarapani E, Dingley J, Liu X, Hoque N, Aquilina K, Porter $\mathrm{H}$, et al. Xenon enhances hypothermic neuroprotection in asphyxiated newborn pigs. Ann Neurol. 2010;68:330-41.

87. Gunn TR, Gluckman PD. Perinatal thermogenesis. Early Hum Dev. 1995;42:169-83.

88. Angeles DM, Wycliffe N, Michelson D, Holshouser BA, Deming DD, Pearce WJ, et al. Use of opioids in asphyxiated term neonates: effects on neuroimaging and clinical outcome. Pediatr Res. 2005;57:873-8.

89. Jacobs SE, Berg M, Hunt R, Tarnow-Mordi WO, Inder TE, Davis PG. Cooling for newborns with hypoxic ischaemic encephalopathy. Cochrane Database Syst Rev. 2013: CD003311.

90. Simbruner G, Mittal RA, Rohlmann F, Muche R, neo.nEURO. network Trial Participants. Systemic hypothermia after neonatal encephalopathy: outcomes of neo.nEURO.network RCT. Pediatrics. 2010;126:e771-8.

91. Natarajan G, Shankaran S, Laptook AR, McDonald SA, Pappas A, Hintz SR, et al. Association between sedation-analgesia and neurodevelopment outcomes in neonatal hypoxic-ischemic encephalopathy. J Perinatol. 2018;38:1060-7.

92. Favie LMA, Groenendaal F, van den Broek MPH, Rademaker CMA, de Haan TR, van Straaten HLM, et al. Pharmacokinetics of morphine in encephalopathic neonates treated with therapeutic hypothermia. PLoS ONE. 2019;14:e0211910.

93. Frymoyer A, Bonifacio SL, Drover DR, Su F, Wustoff CJ, Van Meurs KP. Decreased morphine clearance in neonates with hypoxic ischemic encephalopathy receiving hypothermia. J Clin Pharmacol. 2017;57:64-76.

94. Dean JM, George S, Naylor AS, Mallard C, Gunn AJ, Bennet L. Partial neuroprotection with low-dose infusion of the alpha2-adrenergic receptor agonist clonidine after severe hypoxia in preterm fetal sheep. Neuropharmacology. 2008;55:166-74.

95. Dahmani S, Paris A, Jannier V, Hein L, Rouelle D, Scholz J, et al. Dexmedetomidine increases hippocampal phosphorylated extracellular signal-regulated protein kinase 1 and 2 content by an alpha 2-adrenoceptor-independent mechanism: evidence for the involvement of imidazoline I1 receptors. Anesthesiology. 2008;108:457-66.

96. Ma D, Hossain M, Rajakumaraswamy N, Arshad M, Sanders $\mathrm{RD}$, Franks NP, et al. Dexmedetomidine produces its neuroprotective effect via the alpha 2A-adrenoceptor subtype. Eur J Pharmacol. 2004;502:87-97.

97. Sato K, Kimura T, Nishikawa T, Tobe Y, Masaki Y. Neuroprotective effects of a combination of dexmedetomidine and 
hypothermia after incomplete cerebral ischemia in rats. Acta Anaesthesiol Scand. 2010;54:377-82.

98. Callaway CW, Elmer J, Guyette FX, Molyneaux BJ, Anderson KB, Empey PE, et al. Dexmedetomidine reduces shivering during mild hypothermia in waking subjects. PLoS ONE. 2015;10:e0129709.

99. Tobias JD. Bradycardia during dexmedetomidine and therapeutic hypothermia. J Intensive Care Med. 2008;23:403-8.
100. Ezzati M, Broad K, Kawano G, Faulkner S, Hassell J, Fleiss B, et al. Pharmacokinetics of dexmedetomidine combined with therapeutic hypothermia in a piglet asphyxia model. Acta Anaesthesiol Scand. 2014;58:733-42.

101. O’Mara K, Weiss MD. Dexmedetomidine for sedation of neonates with HIE undergoing therapeutic hypothermia: a singlecenter experience. AJP Rep. 2018;8:e168-73. 